\title{
Employee Motivation and Job Performance: Empirical Evidence from Nigeria
}

\author{
Alase, Gbenga Ayofe $\mathrm{e}^{1, *, \dagger}$ and Akinbo, Tina Martha ${ }^{1, \dagger}$ \\ ${ }^{1}$ Department of Management and Accounting Lead City University Ibadan, Nigeria \\ *corresponding author:alaseg@yahoo.com \\ ${ }^{\dagger}$ Auhtors Contributed equally.
}

\begin{abstract}
Background: This study aims to establish whether there exists a link between employee motivation experiences and job performance. Methodology: TA descriptive research survey was adopted as 206 senior cadre employees of First Bank of Nigeria were sampled using cross-sectional data from a semi-structured questionnaire. Findings: The result revealed that both monetary (competitive salary, salary raise, allowances, bonuses, and percentage profit sharing) and non-monetary (job security, job training, career advancement opportunities, flexible working hours, and retirement benefits) motivational incentives have a significant positive correlation with employee job performance in study organization. Specifically, it was revealed that competitive salary $(R=0.809)$ is the leading monetary motivational factor as job security $(R=0.835)$ tops the ranking for non-monetary motivational factors. It was recommended that study organization will have to employ a mix of both monetary and non-monetary incentives in driving higher performance. Findings also showed that female employees are more motivated by non-monetary incentives $(58 \%)$ while male employees are more motivated by monetary incentives $(61 \%)$. Recommendation: Therefore, management should be more strategic in implementing its yearly financial reward contest and public recognition as this will induce the employees to engage in work behaviour that drives higher-level performance.
\end{abstract}

Key words: Employee Performance, Motivation, Monetary Incentive, Non-monetary Incentive

\section{Introduction}

The dynamism in the twenty-first-century business environment where demand patterns are fast-changing, competition is rising, and customers are demanding more at less time requires that organization adopts strategies built around the organization's customers both internal and external. This trend influences the various rewards systems adopted by different organizations, especially as traditional knowledge links motivation to employee performance and productivity. In recent times, policies on improving the performance of the employees have become one of the concerns of various organization management (George; 2018). This is largely supported by various reports and literature that have suggested a significant loss of revenue by organization due to low employee performance.
Lorincova et al. (2019) argued that poor employee performance in Europe and the United State of America cost EU and US businesses as much $\$ 136$ billion yearly with an upward trend forecasted unless significant changes are made. The emphatic role of employee performance is induced in the value of -performance management service incurred by organizations; such services costs ranged from around $\$ 40$ billion to $\$ 60$ billion yearly between 2011 to 2017 . The issue is more prevalent and worrisome as the gap between the productivity level of employees in emerging and developing economies to that of employees in developed countries is at variance. Authors argued that in developed economies, employees tend to be more productive than their counterparts in developing countries partly owing to the reward system available in such an economy in addition to the prevailing 
environmental factors.

However, the need to boost employee job performance and productivity is a strategic concern for all organizations irrespective of their nature. It is noted that the corporate quest towards gaining and sustaining market share is contingent on the performance of employees which can be improved through effective management of rewards in the organization (Hemakumara; 2020).

It is argued in the literature that the most valuable assets in an organization are the people working in it, interestingly because of human nature, people are also the most difficult resource to handle (Noko and Nwuzor; 2021). This is so because humans have their own individual aspirations and desires that must be achieved and there are set of peculiar behaviour that should be managed if such employees are to play a contributory role in achieving the twin organizational goals of growth and development. Individuals bring their own perspectives, behaviour, morality, and attributes to organizational life and when these characters are efficiently utilized, it will result in improved working relation and employee performance1.

The reverse is usually the case when people are managed without consideration for what motivates them, such actions or steps produce low employee morale and motivation and their low and dismal performance acts to limit the organizational growth and threaten the viability of business(Osabiya; 2015; Noko and Nwuzor; 2021). It has been argued that unsatisfied employees generally produce unsatisfactory results. Similarly, the trend of globalization and the forces behind globalization where the world has become a corporate identity and information circulates within minutes has even made the investigation of the role of employee motivation on their performance a worthwhile effort. As such companies are under pressure to improve their organisational performance in all its dimensions. The opportunities and challenges inherent in leadership and management today are significantly different from that of the past and, the last decade (Neeraj; 2014). Industrial psychologists and management practitioners have thus ignited a burning interest in searching for factors that motivate the employees into higher productivity and how the two affect each other.

Although there has been a growing literature on the link between employee performance and employee motivation in the last two decades, the challenge, however, has been what constitutes the best strategies of motivating the employees into high performance (Hemakumara; 2020). This often implies that the manager or management has to understand each or different categories of an employee in terms of what motivates or demotivates them and build their reward system around that understanding. This understanding and information are difficult to extract and often require the development of the traits of empathy, diligence, and patience on the part of the manager. An understanding of the need of employees can assist the manager/management in designing/planning a reward system to motivate employees for high performance (Hemakumara; 2020).

Such investment can only be justified and applied when there is clear evidence that there exists a positive correlation between improved employee motivation and employee performance or organisational performance. When such evidence is available, the management can provide a rationale for any program aimed at motivating employees. This scenario is however based on the assertion that an organization wants to optimize resource use and in so doing pursue a win-win situation for both the company and employees. If market leadership in the nineteenth and twentieth century is a product of which organization has the biggest and innovative machine in terms of machinery and production line, market leadership in the twenty-first century will therefore be dependent on how creative and innovative the employees working within the organization are. When employees are not motivated to be interested in and actively pursue growth and development, the organization experiences stagnation and is soon edged out of the marketplace. As Olusadum and Anulika (2018) stated 'in today's marketplace, where companies seek a competitive edge, efficient strategic management tools combined with motivation are key for talent retention and performance.

According to (McForson; 2012), employee motivation can be achieved using various incentives. The author surmised that incentives can be grouped into monetary and non-monetary incentives. Monetary incentives include monetary-based factors such as salary, bonuses, cash gift, and allowances which are deemed by management as serving the purpose of spurring employees to higher performance. There are also non-monetary incentives employed in various organizations, such incentives include job security, job enrichment, recognition, and advancement. Non-financial incentives are also referred to as noneconomic motivators. These incentives provide a means of improving employee motivation because they demonstrate to staff that they are considered valuable; they also help promote human dignity and thus raise employee morale for higher productivity.

Most employees who feel their current place of work is not motivating them often leave their place of work. Some reluctantly stayed back not because they are adequately motivated but because they don't have a better alternative at the present moment (in terms of salaries, bonuses, free expense paid trips and some other tips). For a company like First Bank of Nigeria, operating within the banking industry, it is challenging for several reasons; first, competition is intense largely because multinationals (MNCs) believes that Africa and specifically Nigeria provide a good market wave of the nearest future, this further intensified by the fact that low barriers to entry have increased competition.

This study therefore will try to understand and assess the relationship between employee motivation and employee performance from the perspective of both monetary and nonmonetary motivational factors. The rest of the article is organized into a literature review, a methodology section, an analysis and discussion section, and a conclusion.

\section{Review of Related Literature}

\subsection{Conceptual Clarification}

\subsubsection{Motivation}

George (2018) argued that motivation is any influence that portrays, directs, or maintains people's goal-directed behaviors. It refers to the driving force that makes an individual act in a specific way. It is an inner drive that causes an individual to behave in a certain manner'. In another work, James and Stoner8 noted that motivation is those 'psychological characteristics of human that contributes to an individual's level of commitments to the organizational goals and objectives. This very definition is even more important when we consider the importance of employee motivation on employee performance. Hemakumara (2020) expressed the view that motivation is a factor that induced an individual to expend effort towards achieving a particular task. The author further stated that a person's motivation is the determinant of that 
person's level of enthusiasm for specific behavioral patterns and is dependent on the ambition, needs, and wants of such individuals. Motivation could also be expressed in terms of the mental process that has the ability within the short and long run to decide the kind of actions a person takes when subjected to specific stimuli.

Motivation could be seen as the psychological rationale within the employee that serves to induce the manifestation or expression of the negative and positive dynamics of frustration, fixation, anger, withdrawal, team building, excitement by or within a particular employee (Raya; 2015). This is particularly important within the service delivery industry where customer demands are premium, and customers require a high level of service from the organization regardless of the various constraints on the system. It is argued in the literature that an individual's motivation is generally linked to motivational factors that surround them and the motivational factors are usually connected to incentives and rewards systems. The rewards system surrounding an individual can be selfafflicted/accomplishment targets or goals or others influenced. Again, such a collection of rewards and incentives is categorized into monetary and non-monetary. It is important to note that a review of the literature points that even though motivation is key to organisational performance and employee performance, it is not the only driving force to organizational performance. There are other factors influencing performance including skills, knowledge, feelings, emotions, and other inhibiting conditions which are often beyond the employee's sphere of control (Dereje; 2020). Riggio (2014) also pointed out that while the conventional view is to assume that the 'motivated worker is the productive worker', it is also important to know that having a highly motivated workforce is one important factor contributing to employee productivity. This is because of the increasingly complex dynamics of the business environment in which a company must operate.

\subsubsection{Non-monetary motivational factors}

It is important to note that non-monetary motivational factors relate more to employee works environment and relationship between the employees and the organization. Reward system is often built around or considered as being more concerned with the quality of life of an employee and deemed to have a greater and longer-term effect on the employee(Nwannebuife; 2017). Non-monetary motivational factors look beyond shortterm benefits to long-term objectives of the employee and incorporates employees' long-term goals into the organization objectives.

Deci and Ryan (2010) argued that non-monetary motivation is derived within the organization and its relationship with employees. It borders on the existing work ethics, rules, disciplinary process within the organization, interpersonal relationship within the organization and among others. For instance, Mokhniuk and Yushchyshyna (2018) identified the following non-monetary motivational factors are key to employee performance such as receiving verbal or written recognition, receiving additional days off, competitive workplace atmosphere, Having work-related autonomy. Others include public expressions of appreciation, job enlargement, job enrichment, receiving on-site or off-site job training, and existence of team spirit.

\subsubsection{Monetary motivational factors}

Monetary motivational factors are mainly related to financial motivational factors such as wages, financial incentives, and salaries (Armstrong; 2009). Finance plays an important role in the life of employees and has remained a key driver to the productivity of the employees in any organization (Giancola; 2014). Deci and Ryan (2010) noted that money is key to employee motivation, but our perception of its value is influenced by the importance that we also place on reciprocity and fairness, social norms, trust, and trustworthiness. When it comes to monetary rewards for performance the results will also greatly depend on the quality of the performance measures, along with the type of task being rewarded, and the type of reward.

Unlike non-monetary motivation that focuses on the organization relationship with employees and within the employee, monetary motivation is often difficult to sustain for a long period without reassessment and adjustment based on the organization performance and state of the economy. The reason is that what motivates individuals changes with time and the organization must keep with pace to understand changes in what motivates individuals to higher productivity to motivate the employee. In sharp contrast to non-monetary motivation, monetary motivational behaviors are external to the activity or work within consideration. Within the work environment, the view that such monetary motivators as salaries, allowances, and promotional advancement are defined by the organization an individual works for and as such are externally imposed on the individual. Pritchard (2016) also mentioned that monetary factors are designed to be engaged in so that employees would obtain substantial or social rewards. It is therefore argued that individual employees whose major motivation comes from monetary factors will only be motivated if the monetary factors keep coming.

\subsubsection{Employee Performance}

Employee performance over the years has generated a lot of controversy because of the multiplicity of the dimension with which it can be expressed. It is believed that organizational performance can be achieved through employee performances. The implication is that employee productivity can be translated to organizational performance since a high-performing employee means that organization is performing. While Aluko (2014) defined performance as the numerate quantity of work accomplished over a determinate time by the available means of production, Bhatti (2007) defined it as a measure of performance of the utilization of the various factors of production.

In another work, Giancola (2014) shared the view that there is a strong correlation existing between employee performance and the number of inputs and outputs from a clearly defined process. Organisational performance can also be conceptualized as the performance of a business or any other corporate organization which is dependent on the aggregation of the performance of its workers and the efficiency and effectiveness in the use of available organizational resources. The fact that organization has limited resources at their disposal, the motivation of employees becomes a necessity. The fact that there are constraints led to the ironclad rule of performance ratios. Employee performance ratios indicate the extent to which organizational resources are used to produce desired outputs and organization work as much as possible in achieving the ideal ratio even in the face of the constraints of time and resources (Aluko; 2014).

On the other hand, organizational performance relates to all dimensions of work done that is, quality and quantity- and there is a positive correlation between organization performance and a company's competitive edge in the marketplace. There is an associational reduction in costs because previous levels of output can be produced with lesser amounts of resources when the organizational performance ratios are low. Organizational performance can be expressed in terms of qual- 


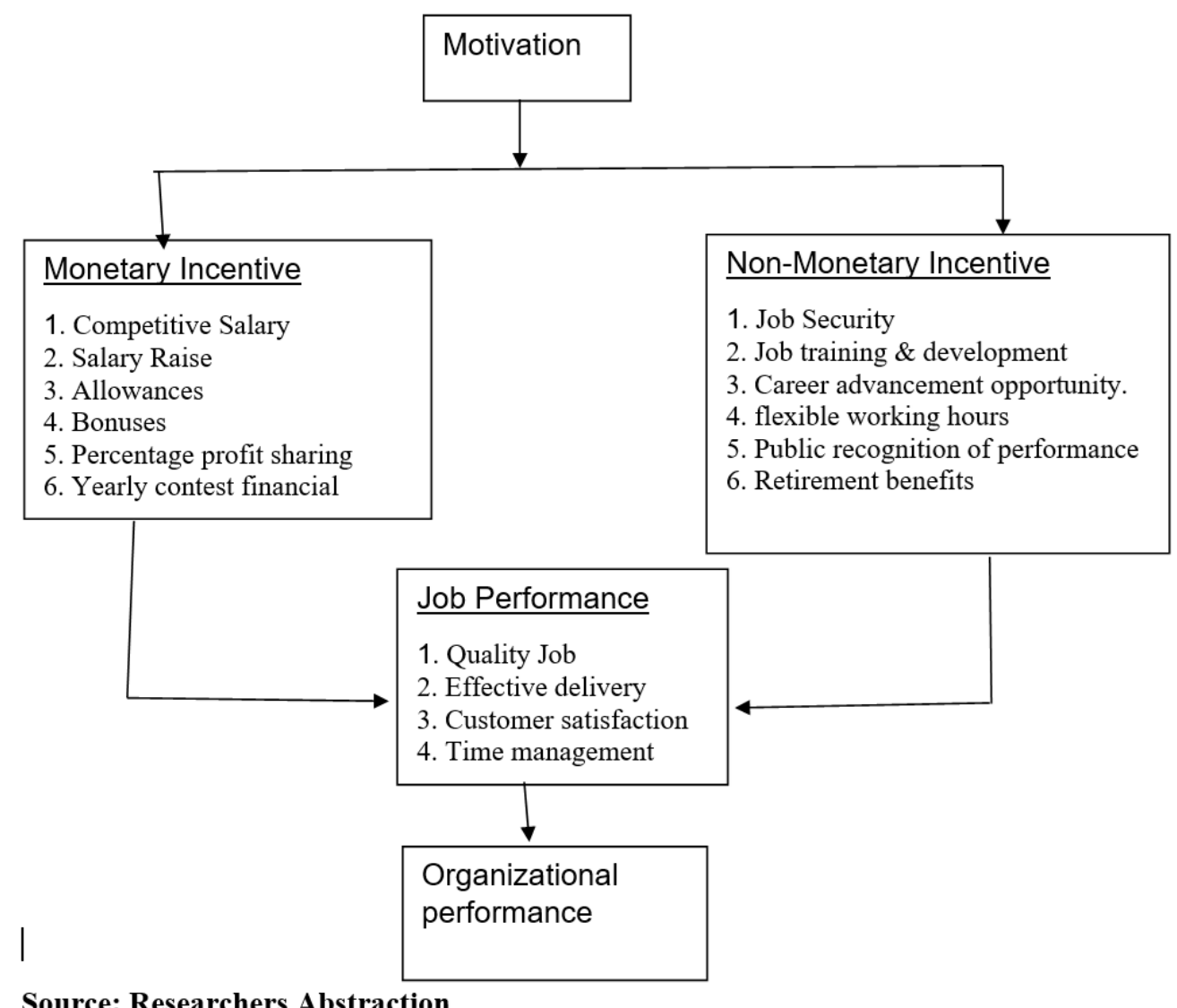

Source: Researchers Abstraction

Figure 1. Conceptual Framework

ity, quantity, time, and cost (Aluko; 2014). A clear point is that organizational performance is dependent on employee performance levels. Worker's level of performance is reliant on the extent to which workers believe that 'certain motivational desires will be met' (George; 2018). The converse is that organizational performance drops whenever employees perceive that their needs cannot be met. In summary, most organization employs both monetary and non-monetary motivational factors to spur their employees into higher performance since it is believed that the higher the employee performance, the higher the organization performance. As such, the conceptual framework guiding the article is as presented in Figure 1.

\subsection{Theoretical framework}

There are several theories that have been developed to explain employee motivation/ behaviour and how these behaviour impact the performance of the employees. Motivation varies over the time span and occurs in different circumstances. The motivational theories can be categorized into process theories and content theories (Osabiya; 2015). Content theories are those frameworks that explain the specific factors which motivate the individuals within the organization. The Osabiya (2015) argued that process theories are extrinsic in nature, and they seek to identify the dynamic nature of the relationship between the variables of interest that constitutes motivation and the actions required to influence behavior and action. For the purpose of this article, a two-process theory will be considered.

Expectancy theory: One of the commonest process theories of motivation is that developed by Victor Vroom expectancy theory. In the words of Scholtz et al. (2016), the expectancy theory defined the diversities within the workplace as it relates to thoughts, concerns, and opinions of workers and how it impacts their attitude and behavior on the job. Vroom's expectancy theory is built around employees' definitive aspirations and hopes. Employees within an organizational setting are mostly intentional about their actions and inaction based on the available information to them and motivational factors, as such, they are committed to efforts they believe will promote their ultimate interest (El-Achi and Sleilati; 2016). The theory believes that efforts or work are positively induced in the workforce if members of the workforce prefer achieving that outcome than not, as such workers prefer to evade negatively valent outcomes. Valence in this sense is the function of the various sources of inspiration guiding employees and their common aspirations.

The crux of Vroom's expectancy theory is that the decision of what outcome should be in the workplace should have a correlational relationship with the specific behaviors, attitudes, and performance that encourages the management in the workplace. The theory has been castigated on two major grounds which are its simplicity and its misleading assumptions. For instance, Guest (2012) argued that the assumption that if management offers an incentive, then workers will automatically act to get the rewards. Such assumption is often misleading and has generated the creation of disincentives for employees.

Goal theory: Goal theory originated from the work of Locke and Latham, and it is an offshoot of the once popular management by the objectives approach. The idea behind 
the goal theory is because it is believed that employees have the ability and should be able to set achievable goals and objectives (Osabiya; 2015; Hemakumara; 2020). The basic premise of this theory is that people's goals or objectives play an important role in determining behavior because 'goals guide people response and action by directing work behavior and performance, and lead to certain feedback'. One of the assumptions of goals motivational theory is that goal setting is more of motivation on its own rather than just a process. As also noted by Stanley (2012), individuals with specific and difficult goals/objectives have proven to be more contributory toward achieving organizational goals and objectives and in the process have higher performance ratings.

The effects of goals theory have practical implications for motivation and performance, the stipulation is that specific performance goal/objectives should be identified, set and staff encouraged to buy into such goals to achieve high-performance levels. Another implication is that the feedback process should be timely in the organization. Goal theory has also been criticized on various points, but most importantly, Lin (2007) asserted that there are instances when goal is only part of the many variables that influence performance. However, the focus on goals most often leads to neglect of the other variables.

\subsection{Empirical Literature}

Several studies have been conducted particularly as it relates to motivation and employee performance. For instance, George (2018) conducted an extensive literature review on the influence of employee motivation on employee performance using an exploratory research approach. The researcher agrees that motivated employees perform better than unmotivated employees in the organization. The researcher concludes that a stressed and depressed heart is negative to the working environment and organization performance whereas a motivated employee brings positive energy in the work environment leading to higher organization performance. A similar study was conducted by Elvina and Chao (2019) on the nexus between employee motivation and work performance using the employees of VTB Bank of Russia as a case study. The study used a quantitative research design collect relevant data and Pearson product moment correlation coefficient was used to test the two hypotheses. Findings revealed that the employees of VTB Bank valued both intrinsic and extrinsic motivation for their industrial performance. However, extrinsic motivation had stronger positive relationship with employees' performance. Following this, the study strongly challenged the employers to improve the payment policies and procedures capable of drawing attention, encouraging, retaining, and satisfying workers in the workplace. The study argued that motivation either extrinsic or intrinsic impacts employee performance, but one would wonder how the author came about that conclusion since they used correlation is establishing a relationship which is not an impact analysis.

Their finding is not consistent with the findings of Dereje (2020) who examined the impact of motivation on employee performance of Fiche General hospital in Pakistan. For instance, while Elvina and Chao (2019) identified extrinsic motivational factors to be more effective in motivating the employee, Dereje (2020) argued that intrinsic factors like employee empowerment exert greater influence on the employee performance within the period under study. Also, like Elvina and Chao (2019), Dereje (2020) employed descriptive survey research design where questionnaire was employed to sample 179 employees which is consistent with
Elvina and Chao. Other studies that employed descriptive survey and found a strong positive impact or linkage with employee performance includes Gift and Obida and Abu (2010) in Yenagoa and Hemakumara (2020) Both studies agrees that employee motivation plays a positive relationship on employee performance in various industries.

On which is more effective between intrinsic and extrinsic motivational tools, Elvina and Chao (2019), using cross-sectional survey research design revealed that both intrinsic and extrinsic motivation had a significant impact on the performance of the employees but argued that extrinsic motivation like competitive salary is more effective compared to others. Other studies like Lorincova et al. (2019) focused more on employee motivation as a tool to achieve sustainability of business processes. The study aimed to investigate and establish the main disparities in the perception of the desired level of motivation, particularly with respect to gender and job category. The study also showed that motivational factors, such as basic salary, workplace atmosphere and good teamwork, greatly motivated all the workers. The researchers advanced the implementation of the results in motivational programs by the employees within the human resource department to enhance effective human resource management.

There are also studies which rather focused on organization performance rather than employee performance. For instance, Ojogbo et al. (2018) conducted research to establish the implications of employee motivation on organizational performance in the Nigerian media industry. The research aimed to determine the factors put in place to motivate employees in the Delta State Broadcasting Service to improve their performance. The study employed a mixed (quantitative and qualitative) methodology was adopted, and the data were collected through questionnaires and interviews.

\section{Methodology}

This study adopts a descriptive research design. Specifically, the study sampled senior and management staffs of First bank of Nigeria Plc in Ibadan, Oyo state. The available population revealed that there were four hundred and twenty-six (426) senior and management staffs of the banks. Taro Yamani sample size determination formular was engaged to arrive at a sample of two hundred and six (206) staffs who were randomly selected through simple random sampling technique.

A five-point Likert scale instrument was designed and distributed to the respondents and were returned to the researcher. Validity and reliability of research instrument was ascertained by a pilot study using 10 employees of the selected organisation. Their feedback was primarily used to make modifications to the final questionnaire used in generating data. Similarly, Cronbach Alfa was conducted on the pilot study data with an average of 0.78 which previous literature considered sufficient (Austin and Adebayo; 2021; Ridwan and Joseph; 2021). The study was analyzed using a combination of descriptive statistics of means, standard deviation, and frequencies alongside inferential statistics such as correlation to determine the impact of employee motivation experiences and their job performance.

\section{Result and Discussion}

This section focuses on the presentation and analysis of the data generated through appropriate data analysis. From the 
Table 1. Descriptive statistics

\begin{tabular}{|c|c|c|c|c|c|c|c|c|}
\hline Age & Freq. & Per.(\%) & Gender & Freq. & Per.(\%) & Experience & Freq. & Per.(\%) \\
\hline Under 30 Years & 9 & 4.5 & Male & 100 & 49.5 & Below 10 Years & 53 & 26.2 \\
\hline 30-39 years & 75 & 37.1 & Female & 102 & 50.5 & $10-20$ Years & 97 & 48.0 \\
\hline 40-49 years & 58 & 28.7 & More & 0 & 0.00 & Above 20 Years & 52 & 25.7 \\
\hline 50-59 Years & 53 & 26.2 & & & & & & \\
\hline 60 Years and above & 7 & 3.5 & & & & & & \\
\hline Education & Freq. & Per.(\%) & Motivated or Not & Freq. & Per.(\%) & Tools of Motivation & Freq. & Per.(\%) \\
\hline Secondary/Diploma & 2 & 1.0 & Yes & 183 & 90.6 & No & 3 & 1.5 \\
\hline Degree (Bsc/HND) & 98 & 48.5 & Don't Know & 4 & 2.0 & Don't Know & 10 & 5.0 \\
\hline Master (MSc/ MBA) & 95 & 47.0 & No & 15 & 7.4 & Yes & 189 & 93.6 \\
\hline Doctor $(\mathrm{PhD})$ & 7 & 3.5 & & & & & & \\
\hline Gender and Motivation Corr. & Male & Female & & & & & & \\
\hline Monetary & $61 \%$ & $39 \%$ & & & & & & \\
\hline Non-monetary & $42 \%$ & $58 \%$ & & & & & & \\
\hline
\end{tabular}

Source: Author

Table 2. Monetary and Non-Monetary Motivation Incentives

\begin{tabular}{|c|c|c|c|c|c|c|c|}
\hline \multicolumn{4}{|l|}{ Monetary Motivation } & \multicolumn{4}{|l|}{ Non- Monetary Motivation } \\
\hline Variables & Mean & Std. Devia. & Rank & Variables & Mean & Std. Devia. & Rank \\
\hline Competitive Salary & 4.54 & 0.499 & 1st & Job Security & 4.45 & 0.655 & 1st \\
\hline Salary Raise & 4.13 & 0.621 & 3 rd & Job training and development & 4.15 & 0.621 & 3rd \\
\hline Allowances & 4.10 & 0.618 & 4th & Career advancement opportunity & 4.11 & 0.618 & 4th \\
\hline Bonuses & 4.30 & 0.655 & 2nd & Flexible working hours & 4.24 & 0.499 & 2nd \\
\hline Percentage Profit sharing & 3.48 & 1.052 & 5 th & Public recognition of performance & 2.98 & 1.052 & 6 th \\
\hline Yearly contest financial reward & 3.11 & 0.851 & 6 th & Retirement benefits & 3.51 & 0.851 & 5 th \\
\hline
\end{tabular}

Source: Author

202 questionnaires completed, findings showed a response rate of $98 \%$. From the result as presented in Table 1 , study revealed that of the 202 sampled respondents, 100 respondents which represent $49.5 \%$ are male while 102 respondents representing $50.5 \%$ are female. The finding is expected since banking industry is the most female friendly industry in Nigeria. It was observed that gender does not have any link in determining the extent an employee will be motivated given that the crosstab correlation between gender and motivation is 0.12 . Similarly, study revealed a correlation coefficient of 0.53 which indicates that gender influences employee motivation as monetary factors motivate male more than the female employees.

Similarly, it was revealed that approximately 4.5 percent of the sampled population are aged 30 year or below, the sample further revealed that approximately $75(37.1 \%)$ of the respondents are aged 30-39 years of age representing most of the age group in the sample. This was closely followed by age 40- 49 which is about 28.7 percent of the respondents, 53 people who is about 26.1 percent are age 50- 59, and lastly, only 7 respondents which is about 3.5 percent of the respondents are age 60 years above. With regards to the respondent experience, it was revealed that 53 of the respondents which is about 26.1 percent has below 10 years of experience, 97 respondents which is about 48 percent has between 11-20 years of experience, and lastly, 52 which is about 25.7 percent have more than 20 years of experience. It was revealed that two respondents representing a percent holds either secondary or certificate programme. 98 of the sample which represent 48.5 percent are degree/HND holders while 97 employees representing 47 percent of the total sampled employees are master (MBA/MSc) holders and lastly, 7 employees about 3.5 percent of the sample are $\mathrm{PhD}$ holders.

Again, the researcher first inquired whether the bank employs any monetary and non-monetary tools in motivating its employee. The result revealed that 189 of the respondents which represents 93.6 percent of the sample agreed that the organization employed both monetary and non-monetary motivational tools in motivating the employees. The study further investigated if the employees are motivated while working in the organization. The findings revealed that 90 percent of the sampled population agreed that they are motivated by the tools employed in the organization as revealed in Table 2 . The result in Table 2 using mean statistics revealed that items mean (competitive salary, salary raise, allowances, bonuses, percent sharing, etc.) are key monetary motivational tools employed by the organization in motivating its employees since their mean value are greater than the average mean of 3.0. Also, all the variables except allowances and percent profit sharing are normally distributed since the ratio between the skewness statistics and standard error is less than 5 percent following the suggestion of Kothari (2009). It was revealed that competitive salary ranks first or the most motivating monetary factor on the sampled respondents. This finding is consistent with the findings of Mokhniuk and Yushchyshyna (2018) who finds that such factors salary, bonuses, allowances are among top monetary motivational factors that improves employee performance.

The result of the non-monetary tools employed in the organization is presented in Table 2 . It was revealed that of all the variables have influence on employee performance with job security topping the list of non-monetary variables motivating the sampled respondents. The finding is consistent also with the work of Mokhniuk and Yushchyshyna (2018); Hemakumara (2020).

To determine whether there is existing relationship between motivation (both monetary and non-monetary) and employee performance. The researcher employed Pearson correlation to estimate the relationship. Specifically, as revealed in Table 3, all the monetary motivational factors with the exemption of yearly contest allowance have strong correlation with 
Table 3. Pearson Correlation Test

\begin{tabular}{llllllll}
\hline & B1 & B2 & B3 & B4 & B5 & B6 & BQ4 \\
\hline Pearson Correlation & .809 & .618 & .650 & .757 & .586 & .115 & \\
N & 202 & 202 & 202 & 202 & 202 & 202 & 202 \\
& C1 & C2 & C3 & C4 & C5 & C6 & CQ4 \\
Pearson Correlation & .835 & .639 & .365 & .534 & .080 & .686 & 1 \\
N & 202 & 202 & 202 & 202 & 202 & 202 & 202
\end{tabular}

Source: Author

employee performance given their correlation coefficient somewhat above 50 percent. Similarly, the non-monetary motivational factor revealed that all the variables except for public recognition has strong correlation with employee performance. Our study is consistent with the work of (Dereje; 2020) and Hemakumara (2020) who also found that motivation and financial incentives improves employee performance but differs from the findings of Wiese and Coetzee (2013) who found a negative relationship between non-monetary motivational incentives and employee performance.

\section{Conclusion and Recommendation}

The study revealed that motivation is a great tool employed in spurring the employee to higher performance. Specifically, it was revealed in the study that monetary and non-monetary tools are employed to motivate employee to higher performance. That monetary incentive tends to motivate the male employee more than it motivates the female employees.

It was further revealed that both monetary and nonmonetary incentives have high correlation with employee performance. The recommendation is that organizations especially those in the service industry like First bank will have to employ a mix of both the monetary and non-monetary incentives in motivating her employees as data revealed that female employees are more motivated by non-monetary incentives while male employees are more motivated by monetary incentives. Secondly, from the empirical result, we see that both yearly financial reward contests and public recognition performed poorly indicating that management should invest their attention into these two areas and do more by appreciating employees with great performance publicly. This will induce the employees to give more to the organisation.

\section{Competing Interests}

Author declare no competing interests.

\section{References}

Aluko, N. (2014). Challenges facing manufacturing companies in Nigeria and Ghana, Kpakpakpa.

URL: $\quad$ http://kpakpakpa.com/spotlight/challenges-facingmanufacturing-in-nigeria-ghana/

Armstrong, D. (2009). Employee reward management and practice, Kogan Page.

Austin, W. and Adebayo, F. (2021). Lean implementation barriers and the duality of lean in an organisation, Applied Journal of Economics, Management and Social Sciences 2(1): 1-8.

Bhatti, K. K. (2007). Impact of employee participation on job satisfaction, employee commitment and employee productivity, International Review of Business Research 3(1): $54-68$.

Deci, E. L. and Ryan, R. M. (2010). The "what" and the "why" of goal pursuits: Human needs and the self-determination of behavior, Psychological Inquiry 11: 227-268.
Dereje, M. L. (2020). Effect of employee motivation on job performance: in case of fiche general hospital, International Journal of Commerce and Finance 6(1): 81-101.

El-Achi, S. and Sleilati, E. (2016). The effect of coaching on employee performance in the human resource management field: the case of the lebanese banking sector, Int J Trade and Global Markets 9(2): 137-169.

Elvina, E. and Chao, L. Z. (2019). A study on the relationship between employee motivation and work performance, IOSR Journal of Business and Management 21(2): 59-68.

George, O. O. (2018). Employee motivation, an organizational performance improvement strategy (a review on influence of employee motivation on organizational performance, JOJ scin. 1(5): 120-124.

Giancola, F. L. (2014). Should hr professionals devote more time to intrinsic rewards?, Compensation \& Benefits Review 46(1): 25-31.

Guest, D. E. (2012). Human resource management and performance: a review and research agenda, International Journal of Human Resource 8(3): 263- 276.

Hemakumara, M. G. G. (2020). The impact of motivation on job performance: A review of literature, Journal of Human Resources Management and Labor Studies 8(2): 24-29.

Kothari, C. R. (2009). Research methodology, (Second Edition), New Age International Publisher Ltd.

Lin, H. F. (2007). Effects of extrinsic and intrinsic motivation on employee knowledge sharing intentions, Journal of Information Science 33(2): 135-149.

Lorincova, S., Starchon, P., Weberova, D., Hitka, M. and Lipoldova, M. (2019). Employee motivation as a tool to achieve sustainability of business process, Sustainability 11(3): 3509-3521.

McForson, J. E. (2012). Impact of motivation on employee motivation, Human Resource Journal 56(5): 17-23.

Mokhniuk, A. and Yushchyshyna, L. (2018). The impact of monetary and non-monetary factors of motivation on employee productivity, Economic Journal of Lesia Ukrainka East European National University 3(12): 94-101.

Neeraj, E. J. (2014). Exploring the job satisfaction and organisational commitment of employees in the information technology environment, Southern African Business Review 15(1): 100-118.

Noko, E. and Nwuzor, J. (2021). Employee and organisational performance: Employees perception of intrinsic and extrinsic rewards system., Applied Journal of Economics, Management and Social Sciences 2(1): 26-32.

URL: https://nokspublishing.com/index.php/AJMSS/article/view/5

Nwannebuife, A. S. (2017). Motivation and organisational productivity: A study of May and Baker Plc, A thesis submitted to College of Development Studies, Covenant University.

Obida, G. W. and Abu, N. (2010). Determinants of foreign direct investment in nigeria: An empirical analysis, Global journal of Human Social Science 26(10): 3-7.

Ojogbo, L. U., Ofili, P. N. and Anthony, D. A. (2018). Employee motivation and its implication on organizational productivity in nigerian media industry, Journal of Applied and 
Advanced Research 3(2): 32-40.

Olusadum, N. J. and Anulika, N. J. (2018). Impact of motivation on employee performance: a study of alvanikoku federal college of eduaction, Journal of Management and Strategy 9(1): 53-56.

Osabiya, B. J. (2015). The effect of employees' motivation on organisational performance, Journal of Public Administration and Policy Research 7(4): 62-75.

Pritchard, R. (2016). Performance appraisal, performance management and improving individual performance: A motivational framework, Management and Organisation Review 2(2): 253-277.

Raya, R. L. (2015). What's in it for me? using expectancy theory and climate to explain stakeholder participation, its direction and intensity, International Journal of Project Management 33(1): 3-14.

Ridwan, D. and Joseph, E. T. (2021). Effects of bank charges on bank's customers saving and income in nigeria, Journal of Economics, Management 27(3): 1-11.

URL: DOI: $10.9734 / J E M T / 2021 / v 273330331$

Riggio, R. E. (2014). Introduction to industrial/ Organisational psychology, Prentice Hall.

Scholtz, B., Mahmud, I. and Ramayah, T. (2016). Does usability matter? an analysis of the impact of usability on technology acceptance in erp settings, Interdiscip. J. Inf. Knowl. Manag. 11(1): 309-330.

URL: http://doi.org/10.28945/3591

Stanley, T. L. (2012). Motivation in today's workplace, Human Resource Journal 55(7): 1-9.

Wiese, M. and Coetzee, R. (2013). The importance of nonfinancial motivators to pharmaceutical sales representatives: A demographic study, Southern African Business Review 17(1): $23-56$. 